\title{
Primary bacterial ventriculitis in adults, an emergent diagnosis challenge: report of a meningoccal case and review of the literature
}

Anaïs Lesourd ${ }^{1,7^{*}} \mathbb{D}$, Nicolas Magne ${ }^{2}$, Anaïs Soares ${ }^{3}$, Caroline Lemaitre ${ }^{4}$, Muhamed-Kheir Taha ${ }^{5}$, Isabelle Gueit ${ }^{1}$, Michel Wolff ${ }^{6}$ and François Caron ${ }^{1}$

\begin{abstract}
Background: Defined by an infection of the ventricular system of the brain, ventriculitis is usually known as a health-care associated infection. In contrast, primary pyogenic ventriculitis complicating community-acquired meningitis is uncommon, and mainly described in infants. Only seven cases that have occured in adults have been found in the international literature.

Case presentation: We report here a new case due to Neisseria meningitidis occurring in an 85 year-old-man. The comparison with previous reports allows to drawn several conclusions: (i) cases occurred in relatively old adults (median age: 65 years); (ii) Streptococcus pneumoniae, N. meningitiditis and Staphylococcus aureus are the leading responsible pathogens; (iii) atypical clinical presentation seems the rule in which meningism often lacks; (iv) in absence of clinical or biological specific parameters, modern brain imaging such as magnetic resonance imaging with gadolinium enhancement is of utmost importance for the diagnosis, leading to anticipate an increase of the diagnosis in the near future, thanks to easier access to such exploration; (v) death or serious sequelae commonly occurred; (vi) prolonged antibiotic courses (6 weeks to 3 months) have been used, without strong rational. In the given case, the patient presented with a lack of meningeal irritation signs. The diagnosis was made by MRI considering a lasting confused state. A four-week antibiotic regimen was successful, combining two weeks of intravenous cefotaxime followed by two weeks of oral levofloxacin much easier to administrate and allowing early rehabilitation.
\end{abstract}

Conclusion: Primary bacterial ventriculitis is a real diagnosis challenge. Larger indications of MRI for bacterial meningitis, particularly in cases with an atypical presentation or poor evolution would certainly increase the number of diagnosis.

Keywords: Meningococcal meningitis, Ventriculitis, Levofloxacin, Cerebral vasculitis, Diagnosis, Magnetic resonance imaging

\section{Backgound}

Ventriculitis most commonly occurs as a complication of external ventricular drains or in patients with ventricular shunts used to relieve increased intracranial pressure associated with hydrocephalus. Such infections are not uncommon (infection rate of ventricular-catheter raising up to $20 \%$ in some series) and are caused by microorganisms

\footnotetext{
* Correspondence: anais.lesourd@chu-rouen.fr

${ }^{1}$ Infectious Disease, Rouen University Hospital, Rouen, France

${ }^{7} \mathrm{CHU}$ Charles Nicolle-Service de Maladies infectieuses et Tropicales, 1 rue de Germont, 76000 Rouen, France

Full list of author information is available at the end of the article
}

involved in foreign body infections such as staphylococci or antibiotic resistant Gram-negative bacilli [1-3].

In contrast, only few cases of primary ventriculitis have been reported, most of them being group $B$ streptococci neonatal infections [4-6]. In a 2017 review by Gronthoud et al. of primary ventriculitis, only six cases have been described in adults including only one due to Neisseria meningitidis [7]. While such infections are supposed to complicate meningitis, surprisingly no meningism was reported in five out of these six cases,

(C) The Author(s). 2018 Open Access This article is distributed under the terms of the Creative Commons Attribution 4.0 International License (http://creativecommons.org/licenses/by/4.0/), which permits unrestricted use, distribution, and reproduction in any medium, provided you give appropriate credit to the original author(s) and the source, provide a link to the Creative Commons license, and indicate if changes were made. The Creative Commons Public Domain Dedication waiver (http://creativecommons.org/publicdomain/zero/1.0/) applies to the data made available in this article, unless otherwise stated. 
despite meningism being an important clinical feature in the diagnosis of meningitis.

We herein report a new case of meningococcal ventriculitis occurring in an elderly and enabling to discuss the interest of fluoroquinolones in such setting.

\section{Case report}

The patient was an 85 year-old-man, with a previous history of atrial fibrillation requiring a long-term curative anticoagulant therapy, renal lithiasis and benign prostatic hyperplasia. He was addressed to the emergency department for a fall in a context of fever at home. As he was afebrile at his arrival in hospital with no evident diagnosis, no antibiotic was introduced. Two days later the patient's condition worsened with high fever $\left(39.4^{\circ} \mathrm{C}\right)$, confusion and altered mental status, without any neck stiffness nor other symptom of meningism. A computed tomography (CT) scan without contrast showed no abnormality. A lumbar puncture revealed a purulent cerebrospinal fluid (CSF) with 5220 white-cells per $\mathrm{mm}^{3}$ (82\% of neutrophils) and rare cocci of undetermined Gram staining on direct microscopic examination. Intravenous antibiotic therapy with cefotaxime and oxacillin was immediately started in combination with adjunctive IV dexamethasone $(10 \mathrm{mg} \mathrm{q}$ $6 \mathrm{~h}$ ). Due to the installation of a comatose state (Glasgow coma score 9/15), the patient was admitted to the intensive care unit, intubated and mechanically ventilated.

After $24 \mathrm{~h}$, the CSF's culture yielded a group B $N$. meningitidis strain with decreased susceptibility to penicillin $(\mathrm{MIC}=0.125 \mathrm{mg} / \mathrm{L}$ for penicillin $\mathrm{G}$ and $=0$. $250 \mathrm{mg} / \mathrm{L}$ for amino penicillin, $\mathrm{MIC}=0.003 \mathrm{mg} / \mathrm{L}$ for cefotaxime, $\mathrm{MIC}=0.002 \mathrm{mg} / \mathrm{L}$ for ciprofloxacin). Cefotaxime alone was continued at $200 \mathrm{mg} / \mathrm{kg} /$ day combined with dexamethasone during the first four days (both according to current national guidelines for bacterial meningitis in adults [8]).

The patient's neurological state progressively improved to regain a vigilant state and was extubated on day 5 of antibiotic therapy. He was discharged to the infectious diseases unit. Nonetheless, he remained confused and somnolent (Glasgow coma score 14/15). Magnetic resonance imaging (MRI) with T2 fluid-attenuated inversion recovery (FLAIR) sequences performed on day 6 revealed the presence of a declivous purulent material inside the lateral ventricles with a moderate dilatation of these structures, not requiring any drainage (fig. 1). This material showed restricted diffusion (decreased apparent diffusion coefficient $[\mathrm{ADC}]$ value) and no magnetic susceptibility artefacts on $\mathrm{T}_{2} *$ sequences, ruling out the possibility of a blood sediment. It also revealed punctiform hyper intensities in T2 weighted sequences and b1000 diffusionweighted imaging (DWI) in multiple vascular territories with cortical and deep white matter distribution. These lesions were characterised by a normal or decreased ADC value and some of them were enhanced after gadolinium injection (fig. 2). All of these findings were consistent with semi-recent ischemic strokes.

Because of this unfavourable outcome, the patient received a prolonged duration of antibiotic therapy, namely cefotaxime for 2 weeks switched to oral levofloxacin (500 mg q $24 \mathrm{~h}$ ) for another 2-week period. After four weeks of antibiotic treatment, the MRI showed a decrease of the purulent debris inside the ventricles with a clear attenuation of the signal (fig. 3). At that time the patient had regained a normal vigilant status. He only suffered from a cerebellar syndrome with a gait disturbance attributed to ischemic cerebellar lesions. After three months of follow-up, the patient's condition had improved, allowing him to walk and to return home, even if the help of a wheelchair was sometimes required.

\section{Discussion and conclusions}

Before the antibiotic era, pathological studies of patients who died from bacterial meningitis have shown that the ventricular fluid usually turned cloudy by the end of the first week of the infection [9]. Nowadays, the incidence of this complication is considered as very low. However, among the six primary ventriculitis cases recently reported by Gronthoud et al., four have been diagnosed during the last ten years [7]. Easier access to modern brain imaging such as MRI has certainly played a role and will increase the number of diagnosis in the near future. MRI including gadolinium-enhanced sequences is the best imaging, particularly in T2 FLAIR sequences which reveal periventricular hyperintensity, an ependymal enhancement and irregular intraventricular debris layering in the occipital horns $[10,11]$. The presence of ventricular debris is reported in 16 out of 17 cases (94\%) of healthcare-associated ventriculitis described by Fukui et al. [11]. According to these authors, an irregular intraventricular debris is quite specific for pus and helps differentiating from a straight level of acute clotted blood [11]. MRI is preferred to a CT-scan, which lacks sensitivity, can mislead the clinician to a diagnosis of intracerebral bleeding or can miss the diagnosis [7]. Thus, MRI should be considered in those patients who fail to improve despite appropriate antibiotic therapy.

Interestingly, adding the current case to the seven found in the literature (the 6 from Gronthoud et al. and one case reported in Japanese language [4]), the median age was of 65 years (rank of 39-85), our patient being the oldest.

Neck stiffness is present in $74 \%$ of patients with bacterial meningitis [12]. However, five out of the six patients reviewed by Gronthoud et al. as well as our patient did not have this sign. While it is well established that some meningococcal meningitis might have an atypical presentation, especially those caused by serogroup W [13], this seems quite the rule in primary pyogenic ventriculitis. 


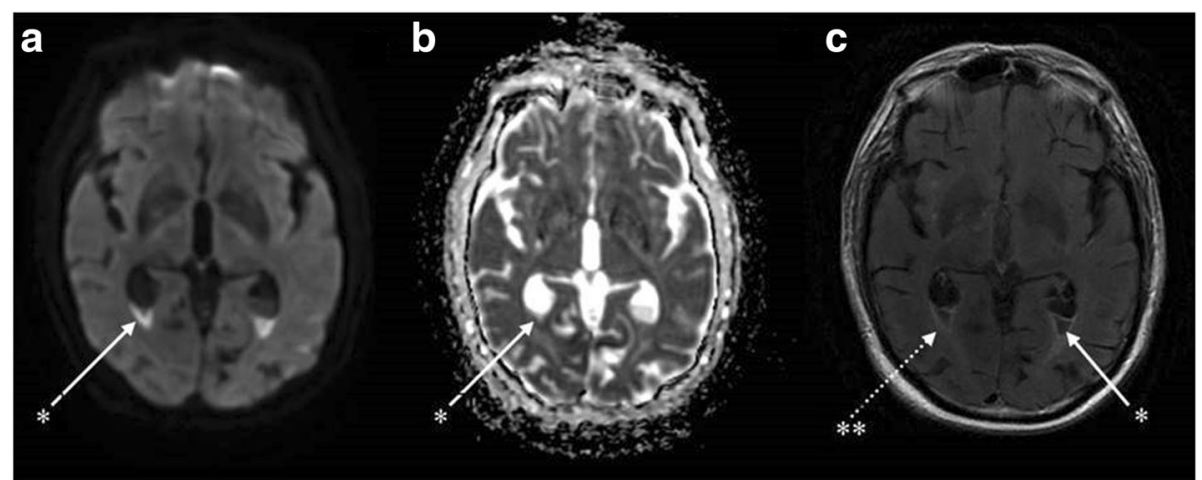

Fig. 1 Brain magnetic resonance imaging (day 6) showing an aspect of ventriculitis in multiple axial sequences. *Irregular declivous intraventricular debris with restricted diffusion in the occipital horns with a moderate dilatation of the lateral ventricles seen in all sequences: diffusion (a), apparent diffusion coefficient (b) and T2 fluid attenuated inversion recovery (FLAIR) gadolinium (1c). **Periventricular hyperintensities and ependymal enhancement in the axial T2 FLAIR with gadolinium enhancement sequence (c)

Our patient had multiple ischemic brain lesions located in various vascular territories, which may correspond to cerebral vasculitis. Routine MRI protocol procedures initially performed did not include angiographic sequences. Retrospectively, volume rendering (VR) 3D-vascular reconstructions were performed with the $\mathrm{T} 1$ gadolinium sequences revealing no sign of proximal vascular stenosis nor thrombosis (fig. 4). Considering the patient was under curative anticoagulant therapy (for his atrial fibrillation), embolic strokes were here ruled out and infectious vasculitis was considered as highly probable. Such complication is relatively common during the course of pneumococcal meningitis (incidence of $9.8 \%$ in a retrospective multicentric study of 162 patients [14]). In contrast, to our best knowledge, no case of meningococcal cerebral vasculitis in adults has been published so far, while one case has been recently reported in a child [15].

While there are precise guidelines for the management of ventricular-catheter related infections [16], we found no recommandations nor expert advice for the management of the treatment of primary bacterial ventriculitis concerning neither the optimal regimen nor its duration. Among the previous cases, precise data on antibiotic treatment are given for only 4 of them: one of the two meningococcal cases was treated for 6 weeks (ceftriaxone $2 \mathrm{~g} \mathrm{q} 12 \mathrm{~h}$ ) [7] and the other for 3 months (ceftriaxone for 17 days followed by 12 weeks of oral moxifloxacin), both of them recovering without any sequelae [4]; a patient with Streptococcus intermedius ventriculitis received a 6-week-combination of cefotaxime and metronidazole [17] and a methicillin-resistant $S$. aureus case received an 8-week course of vancomycin (5 days) switched to oral linezolid (49 days) [18].

A 6 to 12-week duration of treatment is similar to what is commonly recommended for brain abscesses [19] despite the absence of evidence to consider this length essential in ventriculitis (for which the bacterial density as well as the antibiotic diffusion are potentially less problematic). However, given the severity of the disease, a long duration

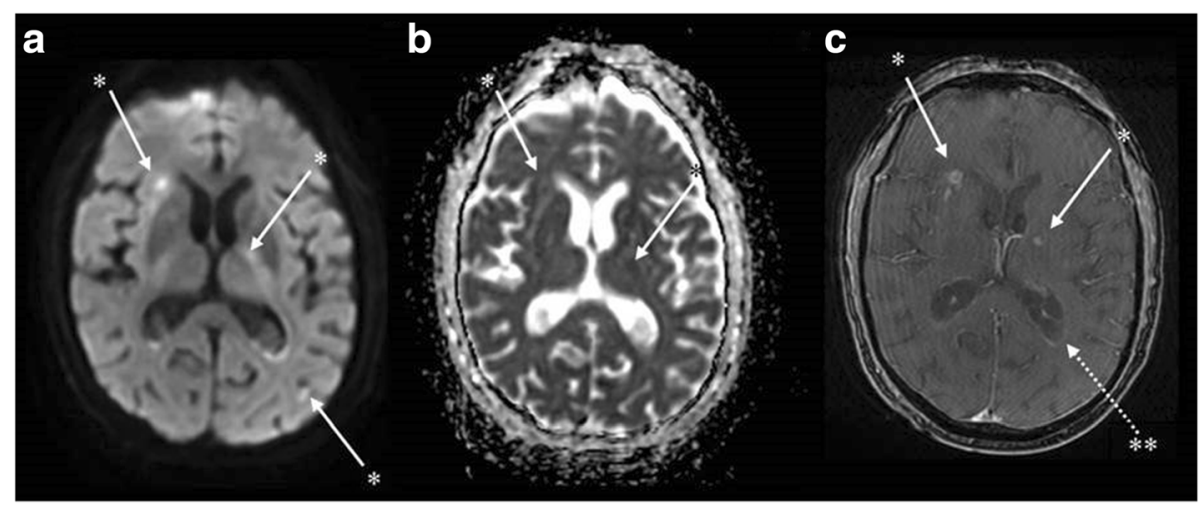

Fig. 2 Brain magnetic resonance imaging (day 6) showing possible cerebral vasculitis in multiple axial sequences. *Punctiform hyperintensities in diffusion-weighted imaging (a) in several vascular territories with cortical and sub-cortical distribution. These lesions appear with a normal or decreased axial apparent diffusion coefficient value (b) and some are enhanced after gadolinium injection in T1 sequences suggesting a blood-brain barrier disruption (c) and consistent with semi-recent ischemic lesions. ${ }^{* *}$ Ependidymal enhancement in T1 with gadolinium enhancement sequences, sign of ventriculitis (c) 


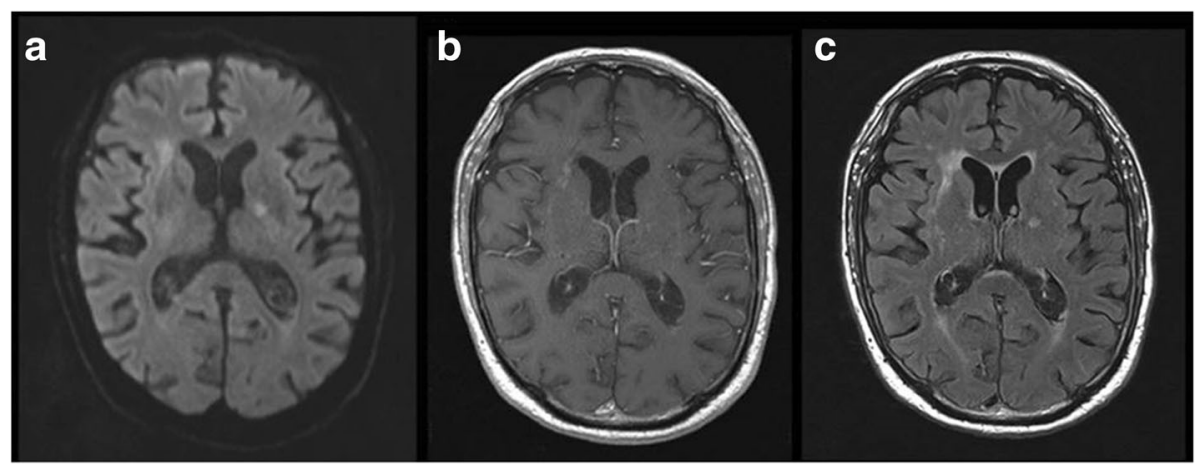

Fig. 3 Brain magnetic resonance imaging at four weeks of treatment in axial multiple sequences. Decrease of the level of debris layering the occipital horns of the lateral ventricles in all sequences: axial diffusion b1000 (a), axial T1 gadolinium (b) and axial T2 fluid attenuated inversion recovery (FLAIR) gadolinium sequences (c). Clear decrease of the periventricular hyperintensities and ependymal enhancement in T1 with gadolinium (b) and T2 FLAIR gadolinium (c) sequences. Decrease of b1000 DWI hyperintensities. No apparition of new ischemic lesions

of antibiotic therapy could be considered providing the tolerance is acceptable.

We chose an initial regimen of third generation cephalosporin secondarily switched to a fluoroquinolone. Even if the patient did not experience any adverse event with cefotaxime, the goal was to shorten the IV treatment duration. Indeed, this oral switch allowed the patient to regain a faster functional autonomy once released from a parenteral perfusion. Levofloxacin, like other fluoroquinolones, achieves good concentrations into the CSF. It was here preferred to moxifloxacin, ensuring a better tolerance particularly in terms of epilepsy and cardiac toxicity $[20,21]$.

In the absence of cerebral suppurative lesions, the treatment was stopped after a total of 4 weeks. This relatively short treatment duration was validated by the absence of relapse.

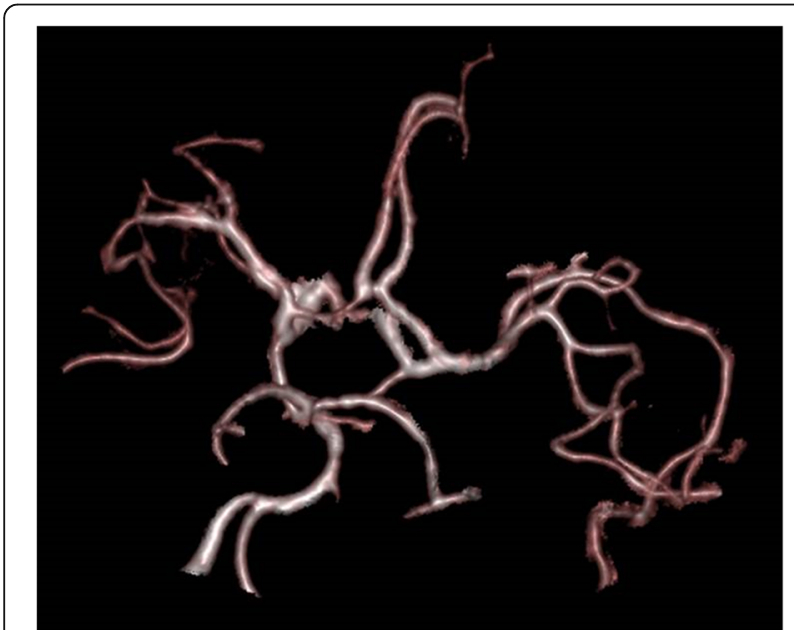

Fig. 4 Magnetic resonance imaging vascular volume rendering reconstruction obtained from the 3D-T1 gadolinium sequences. Absence of proximal vascular stenosis nor thrombosis
Finally, our patient received adjunctive dexamethasone according to current guidelines, i.e., as soon as possible when the lumbar puncture reveals a purulent CSF [22]. Such a treatment has been proven to be beneficial in preventing hearing loss and neurological sequelae in adult purulent bacterial meningitis, particularly those due to Streptococcus pneumoniae [22, 23]. In the current case, dexamethasone however did not prevent the evolution to a ventriculitis probably due to a late diagnosis and treatment initiation in this elderly patient with an initial atypical presentation.

In conclusion, larger indications of MRI for bacterial meningitis, particularly in cases with an atypical presentation or poor evolution, would certainly increase the number of diagnosis of primitive pyogenic ventriculitis as well as of cerebral vasculitis in the near future. For susceptible strains, fluoroquinolones regimens are an attractive antibiotic class allowing an oral easily-totolerate treatment, even if strong evidence for long treatment is lacking.

\section{Abbreviations \\ ADC: Apparent diffusion coefficient; CSF: Cerebrospinal fluid; CT scan: Computed tomography scan; DWl: Diffusion-weighted imaging; FLAIR: Fluid-attenuated inversion recovery; MIC: Minimal inhibitory concentration; MRI: Magnetic resonance imaging; N. meningitidis: Neisseria meningitidis}

\section{Acknowledgements}

Alexandre Morin, neurologist, for his proofreading and help in the discussion.

Availability of data and materials

Data sharing is not applicable to this article as no datasets were generated or analysed during the current study.

\section{Authors' contributions}

AL participated by drafting the manuscript and retrieving the bibliography; NM proofread the section on imagery, figure legends and selected the best images; AS helped in the identification of the meningococcal strain; $\mathrm{CL}$ was the referent medical physician of the patient in the intensive care unit; MKT helped with his expertise in meningococci and contributed to identify the strain and test antibiotic susceptibility; IG participated in the 
management of the anti-infectious treatment as the patient was in infectious diseases care; MW helped with his expertise in the management of bacterial meningitis and made a critical revision of the manuscript, FC was a major contributor in writing the manuscript. All authors read and approved the final manuscript.

\section{Ethics approval and consent to participate}

Not applicable.

\section{Consent for publication}

This case report has obtained the patient's written consent for publication.

\section{Competing interests}

The authors declare that they have no competing interests.

\section{Publisher's Note}

Springer Nature remains neutral with regard to jurisdictional claims in published maps and institutional affiliations.

\section{Author details}

${ }^{1}$ Infectious Disease, Rouen University Hospital, Rouen, France. ${ }^{2}$ Radiology, Rouen University Hospital, Rouen, France. ${ }^{3}$ Microbiology, Rouen University Hospital, Rouen, France. ${ }^{4}$ Intensive Care, Rouen University Hospital, Rouen France. ${ }^{5}$ Institut Pasteur, National Reference Centre for Meningococci and Invasive Bacterial Infections Unit, Paris, France. ${ }^{6}$ Infectious Disease, Bichat-Claude Bernard University Hospital, Paris, France. ${ }^{7} \mathrm{CHU}$ Charles Nicolle-Service de Maladies infectieuses et Tropicales, 1 rue de Germont, 76000 Rouen, France.

Received: 10 August 2017 Accepted: 30 April 2018

Published online: 18 May 2018

\section{References}

1. Blassmann U, Roehr AC, Frey OR, Vetter-Kerkhoff C, Thon N, Hope W, et al. Cerebrospinal fluid penetration of meropenem in neurocritical care patients with proven or suspected ventriculitis: a prospective observational study. Crit Care. 2016:20:343.

2. Beer R, Lackner P, Pfausler B, Schmutzhard E. Nosocomial ventriculitis and meningitis in neurocritical care patients. J Neurol. 2008;255(11):1617-24.

3. Humphreys H, Jenks P, Wilson J, Weston V, Bayston R, Waterhouse C, et al. Surveillance of infection associated with external ventricular drains: proposed methodology and results from a pilot study. J Hosp Infect. 2017; 95(2):154-60.

4. Nakahara H, Oda T, Fukao E, Horiuchi I, Honma Y, Uchigata M. A case of meningococcal meningitis that was difficult to treat owing to concurrent ventriculitis. Rinsho Shinkeigaku. 日本神経学会. 2016;56:344-7.

5. Miyairi I, Causey KT, DeVincenzo JP, Buckingham SC. Group B streptococcal Ventriculitis: a report of three cases and literature review. Pediatr Neurol. 2006;34:395-9.

6. Salmon JH. Ventriculitis complicating meningitis. Am J Dis Child. 1972 https://doi.org/10.1001/archpedi.1972.02110130037005.

7. Gronthoud F, Hassan I, Newton P. Primary pyogenic ventriculitis caused by Neisseria meningitidis: case report and review of the literature. JMM case reports. 2017; https://doi.org/10.1099/jmmcr.0.005078.

8. Société de Pathologie Infectieuse de Langue Française. 17th consensus conference. Consensus conference on bacterial meningitis. Short text. Médecine Mal Infect. 2009;39:175-86.

9. Adams RD, Kubik CS, Bonner FJ. The clinical and pathological aspects of influenzal meningitis. Arch Pediatr. 1948:65:354-76.

10. Ziai WC, Lewin JJ. Update in the diagnosis and Management of Central Nervous System Infections. Neurol Clin. 2008;26(2):427-68.

11. Fukui MB, Williams RL, Mudigonda S. CT and MR imaging features of pyogenic ventriculitis. AJNR Am J Neuroradiol. 2001;22(8):1510-6.

12. Bijlsma MW, Brouwer MC, Kasanmoentalib ES, Kloek AT, Lucas MJ, Tanck MW, et al. Community-acquired bacterial meningitis in adults in the Netherlands, 2006-14: a prospective cohort study. Lancet Infect Dis. 2016;16:339-447.

13. Ladhani SN, Beebeejaun K, Lucidarme J, Campbell H, Gray S, Kaczmarski E, et al. Increase in endemic neisseria meningitidis capsular group W sequence type 11 complex associated with severe invasive disease in England and wales. Clin Infect Dis. 2015;60:578-85.
14. Garcia M, Dinh A, Bretonnière C, Lemaignen A, Cordel H, Abgrall S, et al Not enough of a good thing: worsening of pneumococcal meningitis after corticosteroid discontinuation. Session: OS025 Current issues in bacterial meningitis. ECCMID 2017. https://www.escmid.org/research_projects/ eccmid/past_eccmids/. Accessed 22 Aug 2017.

15. Bouric $P$, Leboucq $P$, Meyer $P$, Jeziorski E. Méningites bactériennes compliquées de vascularites cérébrales, étude rétrospective de 17 cas. Med Mal Infect. 2017;47(4):S26.

16. Tunkel AR, Hasbun R, Bhimraj A, Byers K, Kaplan SL, Scheld WM, et al. 2017 Infectious Diseases Society of America's clinical practice guidelines for healthcareassociated Ventriculitis and meningitis. Clin Infect Dis. 2017:64:701-6.

17. Vajramani $G$, Akrawi $H$, Jones $G$, Sparrow O. Primary ventriculitis caused by Streptococcus intermedius. Br J Neurosurg. 2007;21(3):293-6.

18. Marinelli L, Trompetto C, Cocito L. Diffusion magnetic resonance imaging diagnostic relevance in pyogenic ventriculitis with an atypical presentation: a case report. BMC Res Notes. 2014;7:149.

19. Brouwer MC, Tunkel AR, McKhann GM, van de Beek D. Brain abscess. N Engl J Med. 2014;371:447-56.

20. Carbon C. Comparison of side effects of levofloxacin versus other fluoroquinolones. J Chemother. 2001;47:9-14

21. Chidiac C. Update on a proper use of systemic fluoroquinolones in adult patients (ciprofloxacin, levofloxacin, moxifloxacin, norfloxacin, ofloxacin, pefloxacin). Med Mal Infect. 2015;45(9):348-73.

22. Brouwer MC, Mcintyre P. Prasad K, van de Beek D. In: van de Beek D, editor. Corticosteroids for acute bacterial meningitis: Cochrane Database Syst. Rev; 2015. https://doi.org/10.1002/14651858.CD004405.pub5.

23. Tunkel AR, Hartman BJ, Kaplan SL, Kaufman BA, Roos KL, Scheld WM, et al. Practice guidelines for the Management of Bacterial Meningitis. Clin Infect Dis. 2004:39(9):1267-84

\section{Ready to submit your research? Choose BMC and benefit from:}

- fast, convenient online submission

- thorough peer review by experienced researchers in your field

- rapid publication on acceptance

- support for research data, including large and complex data types

- gold Open Access which fosters wider collaboration and increased citations

- maximum visibility for your research: over $100 \mathrm{M}$ website views per year

At BMC, research is always in progress.

Learn more biomedcentral.com/submissions 